\title{
Liquid-liquid extraction in flow of the radioisotope titanium-45 for positron emission tomography applications
}

Pedersen, Kristina Søborg; Imbrogno, Joseph; Fonslet, Jesper; Lusardi, Marcella; Jensen, Klavs F.; Zhuravlev, Fedor

Published in:

Reaction Chemistry and Engineering

Link to article, DOI:

10.1039/C8RE00175H

Publication date:

2018

Document Version

Peer reviewed version

Link back to DTU Orbit

Citation (APA):

Pedersen, K. S., Imbrogno, J., Fonslet, J., Lusardi, M., Jensen, K. F., \& Zhuravlev, F. (2018). Liquid-liquid extraction in flow of the radioisotope titanium-45 for positron emission tomography applications. Reaction Chemistry and Engineering, 3(6), 898-904. https://doi.org/10.1039/C8RE00175H

\section{General rights}

Copyright and moral rights for the publications made accessible in the public portal are retained by the authors and/or other copyright owners and it is a condition of accessing publications that users recognise and abide by the legal requirements associated with these rights.

- Users may download and print one copy of any publication from the public portal for the purpose of private study or research.

- You may not further distribute the material or use it for any profit-making activity or commercial gain

- You may freely distribute the URL identifying the publication in the public portal 


\title{
Liquid-liquid extraction in flow of the radioisotope titanium-45 for positron emission tomography applicationst
}

\author{
Kristina Søborg Pedersen, ${ }^{a, b \S}$ Joseph Imbrogno ${ }^{b \S}$, Jesper Fonslet, ${ }^{a}$ Marcella Lusardi $i^{c}$, Klavs F. Jensen ${ }^{b, c} *$, and Fedor \\ Zhuravlev $^{\mathrm{a} *}$

\begin{abstract}
A continuous liquid-liquid extraction of ${ }^{\text {nat }} \mathrm{Ti}$ and its PET radioisotope ${ }^{45} \mathrm{Ti}$ into an organic phase from $12 \mathrm{M} \mathrm{HCl}$ is described. The extraction is completely selective with respect to Sc, which is commonly used as a cyclotron target for ${ }^{45} \mathrm{Ti}$ production. A membrane-based separator with integrated pressure control allowed for efficient, reproducible, and robust aqueous/organic phase separation in flow. Optimization studies established a guaiacol-anisole $9 / 1(\mathrm{v} / \mathrm{v}$ ) mixture and a flow rate ratio of $1 / 3$ (aq. to org.), with a residence time of $13.7 \mathrm{~s}$ as the optimal extraction conditions. $90.3 \pm 1.1 \%$ of ${ }^{\text {nat }} \mathrm{Ti}$ were consistently extracted from a $0.01 \mathrm{M}$ solution of ${ }^{\mathrm{nat}} \mathrm{TiCl}_{4}$ and $\mathrm{ScCl}_{3}$, while $84.8 \pm 2.4 \%$ of ${ }^{45} \mathrm{Ti}$ were extracted from $0.03-0.13 \mathrm{M} \mathrm{ScCl}_{3}$ containing picomolar amounts of ${ }^{45} \mathrm{Ti}$ radionuclide, without extracting any $\mathrm{Sc}$ for either system. The organic phase can be directly used for ${ }^{45} \mathrm{Ti}$-radiolabelling as demonstrated by the efficient radiosynthesis of the ${ }^{45} \mathrm{Ti}$-radiolabeled antineoplastic $\left[{ }^{45} \mathrm{Ti}\right]$ (salan)Ti(dipic). This development opens a pathway to perform a continuous and efficient ${ }^{45} \mathrm{Ti}$ recovery and processing using an automated micro or millifluidics setup.
\end{abstract}

\section{Introduction}

Over the past several decades positron emission tomography (PET) has become a medical modality providing the best diagnostic options for cancer available today. ${ }^{1}$ PET radiopharmaceuticals based on radiometals are gaining increasing popularity due to their ability to probe biological processes occurring on timescales from hours to days. ${ }^{2}$ Convenient chelation chemistry and ready availability via the ${ }^{68} \mathrm{Ge}$ generator currently make ${ }^{68} \mathrm{Ga}$ radiometal the most popular choice for radiolabelling of peptides and antibody fragments. ${ }^{3}{ }^{45} \mathrm{Ti}$ is emerging as a promising PET radiometal due to its $85.7 \%$ positron branch, negligible secondary radiation, and facile production. ${ }^{4}$ The 3 -hour half-life of ${ }^{45} \mathrm{Ti}$ compares favorably with that of ${ }^{68} \mathrm{Ga}(68 \mathrm{~min})$ and can allow for longer transport distances. Furthermore, the sharper PET images of ${ }^{45} \mathrm{Ti}$ due to its lower $\beta^{+}$endpoint energy (1.04 MeV for ${ }^{45} \mathrm{Ti}$ vs. $1.90 \mathrm{MeV}$ for ${ }^{68} \mathrm{Ga}$ ) can be especially advantageous for a small-animal PET. A number of small molecule ${ }^{45} \mathrm{Ti}$ compounds were previously synthesized and used for PET imaging $^{5-7}$ and radiotracing. ${ }^{8}$ Our research efforts are directed towards increasing the adoption of the ${ }^{45} \mathrm{Ti}$ PET by developing efficient ${ }^{45} \mathrm{Ti}$ recovery procedures and water-compatible chelation chemistry.

The bombardment of naturally monoisotopic scandium with low energy protons from a medical cyclotron via the ${ }^{\text {nat }} \mathrm{Sc}(p, n){ }^{45} \mathrm{Ti}$ nuclear reaction is an attractive ${ }^{45} \mathrm{Ti}$ production route. ${ }^{9-11}$ Recovery of a radiometal is the first post-production step, which for a highly hydrolyzable metal such as $\mathrm{Ti}$, becomes critical. Currently, the solid phase extraction from acidic solutions onto a cation or anion-exchange resin is the predominant way to separate the ${ }^{45} \mathrm{Ti}$ from its Sc matrix. We

\footnotetext{
Technical University of Denmark, Center for Nuclear Technologies,

Frederiksborgvej 399, Building 202, 4000 Roskilde, Denmark, tel: +45 46775337 fax: +4546775347

b. Department of Chemical Engineering, Massachusetts Institute of Technology, Cambridge, MA, 02139, USA

c. Department of Materials Science and Engineering, Massachusetts Institute of Technology, Cambridge, MA, 02139, USA

$\S$ K.S.P. and J.I. contributed equally to this work

+ Electronic Supplementary Information (ESI) available: Separator material optimization and solvent selection.
}

and others previously used the PEG-functionalized diol, cation-exchange ${ }^{5-7}$ and hydroxamate ${ }^{12}$ resins. With the recent advances and availability of automation, there is a strong drive to implement advanced chemical separation techniques compatible with micro and millifluidics.

One of these techniques is liquid-liquid extraction (LLE). In recent years LLE in micro-scale flow has received increasing attention ${ }^{13}$. Continuous extraction has been successfully demonstrated in rectangular microreactors ${ }^{14}$, three-phase microfluidic chip ${ }^{15}$, porous capillary ${ }^{16}$, and capillary membranebased devices ${ }^{17}$ In the area of radiopharmaceutical production and research, LLE is underdeveloped since up until now LLE was primarily performed manually, entailing significant radiation exposure to personnel. Due to recent developments in flow chemistry, LLE can now be carried out continuously by exploiting the high mass transfer of slug flow followed by complete phase separation utilizing the wettability of polymer membranes. ${ }^{18}$ This system has been used for multi-stage counter-current LLE of small organics and solvents, ${ }^{19}$ solvent exchange and purification during continuous pharmaceutical synthesis, ${ }^{20,21}$ and quantum dot purification..$^{22}$ In this work, LLE followed by a single stage of membrane-based phase separation was utilized to purify both non-radioactive and radioactive $\mathrm{Ti}$ from Sc metal continuously. This process does not require any manual operation after initial setup and therefore is highly applicable to radioactive systems, like the one described here.

The membrane separators used herein have been published for various applications, but are briefly described here. ${ }^{18,19,22}$ The membrane separator module consists of two main components: a polymer microfiltration (MF) membrane and a thin plastic diaphragm (Fig. 1).

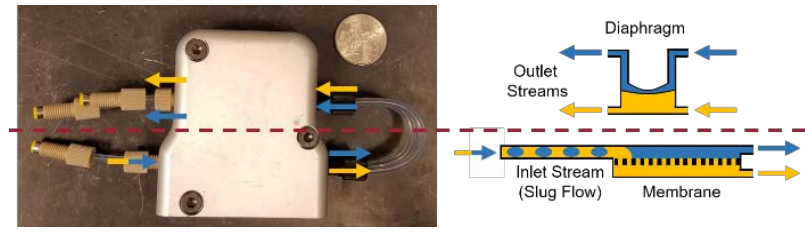

Fig. 1. Schematic diagram showing flow paths of membrane separator alongside a photograph of an actual separator. The aqueous phase is shown in blue (retained phase) and the organic phase is shown in yellow (permeated phase). U.S. quarter is shown for scale 
The diaphragm, a thin, chemically compatible perfluoroalkoxy alkane (PFA) polymer, acts to modulate the pressure between the aqueous and organic sides of the membrane. Various diaphragm thicknesses allow one to control the pressure the diaphragm exerts on the system, known as $P_{\text {dia. }}$. The upper and lower bounds for operating this system while achieving complete phase separation correspond to the capillary, $\mathrm{P}_{\text {cap }}$, and permeation pressures, $\mathrm{P}_{\text {perm }}$, respectively. A more accurate model for the upper and lower pressure bounds that accounts for the pore size distribution and the tortuosity has been recently published. ${ }^{23}$

The interfacial tension between the two phases is also critically important since it cannot be varied without chemical additives or changing solvents. It is essential to stay within the operating range of the system; otherwise incomplete phase separation will occur. The capillary and permeation pressures are only the theoretical upper and lower limits, respectively, of the system; therefore it is important to note that the actual operating range where complete separation will occur usually exists in a smaller region when using a real system. Therefore, after the radioisotope of interest is selectively extracted into one of the phases (organic or aqueous), the membrane separator will completely separate the two phases, and the radioisotope-enriched phase can be used directly for downstream radiolabelling. By combining two or more membrane separators, multiple LLEs can be easily carried out in series, such as extraction into the organic phase and backextraction into the aqueous phase.

In this contribution, we describe the use of a single membrane separator for the facile purification of the radioisotope ${ }^{45} \mathrm{Ti}$ in flow directly after production with a total system residence time less than $1 \mathrm{~min}$ and a residence time of $\leq 15 \mathrm{~s}$ for the LLE mixing step. To demonstrate that the extracted ${ }^{45} \mathrm{Ti}$ can be used directly for radiolabelling after the LLE in flow, we performed a radiosynthesis of $\left[{ }^{45} \mathrm{Ti}\right]$ (salan)Ti(dipic), an anti-tumour compound previously used for ${ }^{45}$ Ti-radiotracing. ${ }^{8}$

\section{Experimental}

\subsection{Materials}

Guaiacol, anisole (99\%), 1-octanol (99\%), titanium (IV) chloride (neat), titanium (IV) chloride solution $(0.09 \mathrm{M}$ in $20 \% \mathrm{HCl}$ ), hydrochloric acid (37\%), sulfuric acid (95.0-98.0\%), and pyridine-2,6-dicarboxylic acid (dipic) (98\%) 1,2-decandiol (98\%), 2,3-napthalene diol (98\%) , $\alpha, \alpha, \alpha$-trifluorotoluene (99\%), 1,1,1,3,3,3-hexafluoropropanol (99\%), $1 \mathrm{H}, 1 \mathrm{H}, 2 \mathrm{H}, 2 \mathrm{H}$ perfluoro-1-octanol were purchased from Sigma Aldrich and used without further purification. TLC plates (Silica gel on TLC Al foil) were also purchased from Sigma Aldrich. Scandium (III) chloride (anhydrous, 99.9\%) and scandium foil (250 $\mu \mathrm{m}, 99.9 \%$ pure, rare earth analysis) were purchased from Alfa Aesar. Custom Ti and Sc ICP standards were purchased from Inorganic Ventures (100 ppm of each metal in a $5 \% \mathrm{HCl}$ solution). Salan ${ }^{24}$ and (salan)Ti(dipic) ${ }^{25}$ were synthesized according to the literature procedures. The membrane separator module was similar to those manufactured by Zaiput Flow Technologies. Pall PTFE membranes were used for all experiments $(47 \mathrm{~mm}$ diameter, 0.1/0.2/0.5 $\mu \mathrm{m}$ pore size, polypropylene (PP) support for the $0.1 / 0.2 \mu \mathrm{m}$ pore sizes). PFA diaphragms (0.001"/0.002"/0.005" (0.0254/0.0508/0.1270 mm)) were purchased from McMaster Carr. All PFA tubing (1/16" OD, 0.03 " ID) was purchased from Idex Health and Science. PTFE static mixers were purchased from Stamixco. The $15 \mathrm{~mL}$ plastic centrifuge tubes with screw caps were purchased from VWR.

\subsection{Instrumentation}

The solutions for the continuous membrane-based separation were pumped using either the KDS 100 Legacy Syringe (radioactive experiments) or the Harvard Apparatus PHD 2000 Programmable and Infusion syringe pumps (nonradioactive experiments). The NMR spectra were taken on Agilent $400 \mathrm{MR}$ operating at $400.445 \mathrm{MHz}\left({ }^{1} \mathrm{H}\right)$. The radioactivities were measured on the $\mathrm{CRC}-55 \mathrm{tR}$, Cll Capintec, Inc. dose calibrator. Radio-TLC was performed with a Raytest MiniGita TLC scanner using chloroform /ethyl acetate (1/1, $\mathrm{v} / \mathrm{v}$ ) as a mobile phase. The HPLC and radio-HPLC analyses were performed on a Hitachi Chromaster equipped with a Carrol\&Ramsey 105-S radio-detector and a Hitachi 5430 double diode array detector. Column: Phenomenex Luna $3 \mu$ C18(2) (100 ̊, $100 \mathrm{~mm} \times 2.00 \mathrm{~mm})$. Flow: $0.5 \mathrm{~mL} / \mathrm{min}$. Eluents: (A) $0.1 \%(\mathrm{v} / \mathrm{v}) \mathrm{CF}_{3} \mathrm{COOH}$ in Milli-Q water, (B) $0.1 \%(\mathrm{v} / \mathrm{v})$ $\mathrm{CF}_{3} \mathrm{COOH}$ in $\mathrm{CH}_{3} \mathrm{CN}$. The radiochemical identity of $\left[{ }^{45} \mathrm{Ti}\right]$ (salan)Ti(dipic) was established by comparing its retention time with that of its natural abundance isotopomer. The radiochemical conversion (RCC) was determined by radio-HPLC or radio-TLC and calculated as: RCC $=\left(\right.$ Area $_{\text {product }} /$ Total Area $) *$ $100 \%$.

The extent of extraction (Extraction \% in Fig. 4-5) was determined relative to titanium initially present in the aqueous phase $\left(100 \% *[\mathrm{Ti}]_{(\mathrm{org})} /[\mathrm{Ti}]_{(\mathrm{aq})}\right)$ using inductively coupled plasma atomic emission spectroscopy (ICP-AES, Agilent 5100 Dual View) of the aqueous phase. Samples of the aqueous phase were collected before the LLE and after 5, 15, 30, and 45 minutes of LLE. $0.35 \mathrm{~mL}$ of each sample was digested in $5 \mathrm{~mL}$ with $10 \%(\mathrm{v} / \mathrm{v}) \mathrm{H}_{2} \mathrm{SO}_{4}$ for 6 hours at $160{ }^{\circ} \mathrm{C}$. $2.7 \mathrm{~mL}$ of the digested sample was diluted up to $10 \mathrm{~mL}$ with Milli-Q water to reach a total acid concentration of $5 \%(\mathrm{v} / \mathrm{v})$. Calibration standards (Inorganic Ventures) were prepared to match the sample matrix with concentrations of 22.2, 18, 15, 10, and 5 $\mathrm{ppm} \mathrm{Ti}$ and Sc and run prior to every set of samples. Samples were analyzed in radial view at a viewing height of $8 \mathrm{~mm}$. Because organic solutions are not directly amenable to the ICP analysis, the extraction to the organic phase was calculated from the concentration of $\mathrm{Ti}$ and $\mathrm{Sc}$ in the aqueous phase $\left(C^{\mathrm{Ti}, S C}\right)$ before and after the LLE by $E=\left(\left(C^{T i, S C}\right.\right.$ before LLE $-C^{T i, S C}$ after LLE) $/ \mathrm{C}^{\mathrm{Ti}, \mathrm{SC}}$ before LLE) $\cdot 100 \%$.

\subsection{Radiochemistry}

${ }^{45} \mathrm{Ti}$ was produced by $10-20 \mu \mathrm{A}$ proton irradiation of $30-60 \mathrm{mg}$ scandium foil, for 5-15 min using a GE PETtrace cyclotron. To 
minimize coproduction of the ${ }^{44} \mathrm{Ti}$ (half-life $=60.0$ years), a 500 $\mu \mathrm{m}$ thick aluminium foil was used to degrade the incidental 16 $\mathrm{MeV}$ beam to approximately $13 \mathrm{MeV}$. The ${ }^{45} \mathrm{Ti}$-loaded foils were dissolved in $3 \mathrm{~mL} 12 \mathrm{M} \mathrm{HCl}$, and the reaction mixture was filtered through a glass frit and further diluted with $12 \mathrm{M} \mathrm{HCl}$ to a total of $10-20 \mathrm{~mL}$. The radioisotope ${ }^{45} \mathrm{Ti}$ was extracted from its $\mathrm{HCl}$ solution into the organic phase using either shaking/spinning (batch) or slug flow (continuous) procedures. The organic phase was separated and mixed with a $0.06 \mathrm{M}$ solution of salan and dipic in pyridine. The solution was stirred at $60^{\circ} \mathrm{C}$ for $15 \mathrm{~min}$ to complete the formation of $\left[{ }^{45} \mathrm{Ti}\right]$ (salan)Ti(dipic) and then analyzed.

\subsection{Batch LLE and separation}

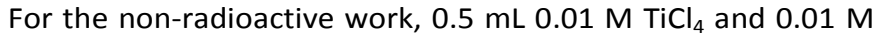
$\mathrm{ScCl}_{3}$ in $37 \% \mathrm{HCl}$ was mixed with $1.5 \mathrm{~mL}$ guaiacol/anisole, 9/1 $(\mathrm{v} / \mathrm{v})$, and shaken for 2 minutes in a centrifuge tube. The phases were allowed to separate by gravity. The concentration of $\mathrm{Ti}$ and $\mathrm{Sc}$ in the aqueous phase before and after the LLE was measured by ICP-AES.

For the ${ }^{45} \mathrm{Ti}$ work, a centrifuge tube was charged with $2 \mathrm{~mL}$ of the solution of ${ }^{45} \mathrm{Ti}(10-50 \mathrm{MBq})$ in $37 \% \mathrm{HCl}$ and $2 \mathrm{~mL}$ of the organic phase. The mixture was shaken vigorously, spun for 15 minutes, and centrifuged at $4000 \mathrm{rpm}$ to separate the phases. Then, the radioactivity in each phase was measured.

\subsection{Continuous membrane-based LLE and separation}

The LLE and phase separation in flow were performed using a membrane-based separator with a PFA diaphragm for integrated pressure control (with this design, the transmembrane pressure is intrinsically linked with the backpressure applied by the diaphragm). A flow schematic of the experimental setup is shown (Fig. 2). The two phases passed

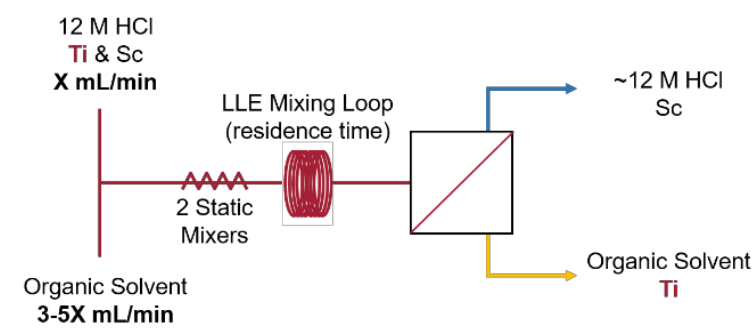

Fig. 2. Schematic of the setup used for continuous phase separation. The aqueous and the organic phases were combined through a tee and mixed with two static mixers and mixing tubing. The aqueous phase was retained by the membrane, while the organic phase permeated through the membrane. Ti was selectively extracted over Sc into the organic phase.

through PFA tubing (1/16" OD, 0.03" ID) and were mixed in a PEEK tee, followed by two 10 element PTFE static mixers (3.4 $\mathrm{cm}$ total length, placed inside of a short length of $1 / 8$ " OD, $1 / 16$ " ID PFA tubing) and various lengths of PFA mixing tubing, which were used to control the residence time of the LLE. After the static mixers, steady slug flow was developed and passed through the LLE mixing loop and finally into the membrane separator, where the organic phase permeated the membrane while the aqueous phase was retained. Different diaphragm thicknesses, membranes, and flow rates were tuned to achieve complete separation of the aqueous and organic phases.

\section{Results and discussion}

\subsection{LLE in batch mode: preliminary experiments}

Several practical considerations merit emphasis at the outset. In radiochemistry, ${ }^{45} \mathrm{Ti}$ is obtained as a strongly acidic solution after digestion of the cyclotron-irradiated Sc foil in concentrated $\mathrm{HCl}$. High acidity is necessary because when $\left[\mathrm{H}^{+}\right]$ $<11 \mathrm{M}$ the titanium speciation diagram becomes populated by titanyl species, ${ }^{26}$ unusable for radiolabelling. Such a high acidity limits the choice of extractants and diluents to nonbasic compounds. The oxophilicity of titanium further narrows it down to O-donors, such as alcohols, diols, and phenols, and certain organic acids. Finally, high acid concentration increases the phase miscibility and lowers the interfacial tension, making phase separation potentially more complicated. ${ }^{26}$ Our preliminary screening experiments were performed in batch using gravity separation and were inspired by a report claiming that ${ }^{45} \mathrm{Ti}$ can be extracted from aqueous $\mathrm{HCl}$ into 1-octanol, presumably as [ $\left.{ }^{45} \mathrm{Ti}\right] \mathrm{Ti} n$-octyloxide [1] (Fig. 3). ${ }^{27}$
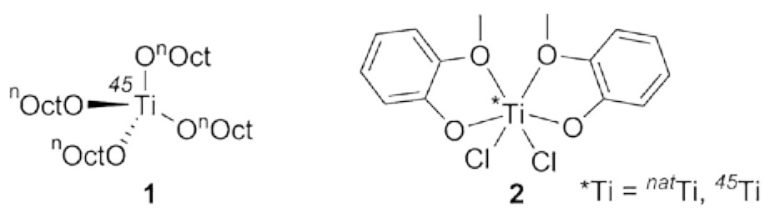

Fig. 3. The putative Ti species extracted in 1-octanol (1) and guaiacol (2).

Table 1. Liquid-liquid batch extraction of ${ }^{45} \mathrm{Ti}$ from cyclotron-irradiated $\mathrm{Sc}$ foil digested in $37 \% \mathrm{HCl}$, except entry $1^{\mathrm{a}}$. $\mathrm{EE}$ is the extraction efficiency, $\mathrm{EE}=100 \% * \mathrm{~A}_{\text {(org) }} / \mathrm{A}_{\text {(orgaq) }}$, where $\mathrm{A}_{\text {(org) }}$ and $\mathrm{A}_{\text {(orgaa) }}$ is the activity of ${ }^{45} \mathrm{Ti}$ in the organic and organic + aqueous layers, correspondingly, as measured by a radiation detector

\begin{tabular}{lll}
\hline Entry & Extraction system (organic phase) & $\mathrm{EE}(\%)$ \\
\hline 1 & 1-octanol, neat ${ }^{\mathrm{a}}$ & 4 \\
2 & 1-octanol, neat & 47 \\
3 & 1,2-Decanediol, 0.1M in 1-octanol & 54 \\
4 & 2,3-naphthalene diol, 0.1 M in 1-octanol & 52 \\
5 & $\mathrm{C}_{10} \mathrm{~F}_{21} \mathrm{CH}_{2} \mathrm{CH}(\mathrm{OH}) \mathrm{CH}_{2} \mathrm{OH}^{\text {b }}$ & $<0.1$ \\
6 & Guaiacol, neat $^{2}$ & 75 \\
${ }^{\mathrm{a}} 20 \% \mathrm{HCl} ;$ & ${ }^{\text {b }}$ trifluorotoluene/hexafluoropropanol $(1 / 1, \mathrm{v} / \mathrm{v})$ & \\
\hline
\end{tabular}

We observed little extraction when a solution of ${ }^{45} \mathrm{Ti}$ in $20 \%$ $\mathrm{HCl}$ was used (Table 1, entry 1). Using $37 \% \mathrm{HCl}(12 \mathrm{M})$ significantly improved the extraction. 1,2-Decanediol used as co-extractant as a $0.1 \mathrm{M}$ solution in 1-octanol gave only a slight improvement over neat 1-octanol. 2,3-naphthalene diol, reported to extract $\mathrm{Ti}$ at $\mathrm{pH}=4,{ }^{28}$ showed similarly modest performance. (Table 1, entries 3 and 4). During these batch extractions, we noticed a significant increase in the volume of the 1-octanol phase suggestive of conc. $\mathrm{HCl}$ migrating into the organic phase. In an attempt to improve the phase separation we turned to perfluorinated extractants. ${ }^{29}$ Disappointingly, the 
fluorous analog of 1-octanol, $\mathrm{CF}_{3}\left(\mathrm{CF}_{2}\right)_{5} \mathrm{CH}_{2} \mathrm{CH}_{2} \mathrm{OH}$ formed an emulsion. A $0.05 \mathrm{M}$ solution of $\mathrm{C}_{10} \mathrm{~F}_{21} \mathrm{CH}_{2} \mathrm{CH}(\mathrm{OH}) \mathrm{CH}_{2} \mathrm{OH}$ in trifluorotoluene / hexafluoropropanol (1/1, v/v) failed to extract any ${ }^{45} \mathrm{Ti}$. (Table 1 , entry 5). Previously, it was reported that guaiacol (o-methoxyphenol) easily forms a moisturesensitive but isolable complex cis- $\left[\mathrm{TiCl}_{2}\left(\eta^{2} \text {-guaiacolato }\right)_{2}\right]$ with titanium tetrachloride. ${ }^{30}$ Gratifyingly, using neat guaiacol as an extractant, we were able to extract $75 \%$ of activity into the organic phase, presumably as [2] (Fig. 3). Next, we translated the batch experiments into fully continuous flow experiments.

\subsection{LLE of ${ }^{\text {nat }} \mathrm{Ti}$ in flow: system optimization}

In order to find the optimum extraction conditions, the diaphragm thickness, membrane pore size, organic phase composition, flow rate ratios, and residence times were varied. Once the optimal materials and conditions were determined, a study was conducted to determine the shortest residence time, thereby minimizing the dead volume and overall processing time, while still maintaining high extraction. The residence time was varied by varying the length of the mixing tubing after the static mixers while maintaining a constant flow rate. All systems were operated for $60 \mathrm{~min}$ each and samples were collected every $15 \mathrm{~min}$.

Complete separation requires both the diaphragm thickness and membrane pore size to be chosen so that $P_{\text {dia }}$ lies between the $P_{\text {cap }}$ and $P_{\text {perm }}$ pressures. In general, low interfacial tension mixtures often require smaller pore size membranes and thinner diaphragms. In these experiments, polytetrafluoroethylene (PTFE) membranes were tested using the following pore sizes $0.1,0.2$, and $0.5 \mu \mathrm{m}$. Three different diaphragm film thicknesses were also tested: 0.001", 0.002", and $0.005 "$ " $0.025 \mathrm{~mm}, 0.051 \mathrm{~mm}$, and $0.127 \mathrm{~mm}$ ).

Since guaiacol had shown the most selective and highest extraction efficiency for Ti over Sc in batch, it was chosen as a candidate for translation into flow. A solution of $0.01 \mathrm{M} \mathrm{TiCl}_{4}$ and $0.01 \mathrm{M} \mathrm{ScCl}_{3}$ in $37 \% \mathrm{HCl}$ was extracted into guaiacol using the membrane separator. Occasional retention and/or breakthrough of the aqueous into the organic phase was observed with a $0.2 \mu \mathrm{m}$ PTFE/PP membrane, 0.002" diaphragm thickness, and $0.2 \mathrm{~mL} / \mathrm{min}$ total flow rate. The situation was remedied by adding various amounts of anisole, which is structurally similar to guaiacol but acted to increase the interfacial tension. The COSMO-RS calculations ${ }^{31}$ showed that the interfacial tension is expected to increase linearly with the increase in the volume fraction of anisole (Figure S1, see the $\mathrm{ESI}+$ ). These organic mixtures were used to extract $\mathrm{Ti},(0.01 \mathrm{M})$ from $37 \% \mathrm{HCl}$ at a total flow rate of $0.20 \mathrm{~mL} / \mathrm{min}$ and aqueous to organic flow rate ratios of $1 / 5,1 / 3$, and $1 / 1(\mathrm{v} / \mathrm{v})$. Corresponding flow rates and extraction performance are shown in Table S1, see the ESIt. To determine the scalability of the process, the total flow rate was then increased five-fold. Therefore, a total flow rate of $1.00 \mathrm{~mL} / \mathrm{min}$ was used, while maintaining the same flow rate ratios and residence times.

The separation results for both 1-octanol and $1 / 1$ guaiacol/anisole using different membranes and diaphragm thicknesses are shown in Table S2, see the ESIt. Although the guaiacol/anisole mixture performed much better than 1octanol, its extraction efficiency was not high enough. Therefore, the ratio of guaiacol to anisole was varied as well, as summarized in Table 2. After an optimal system was developed, the residence time of mixing was varied to minimize the dead volume and decrease the total amount of time spent in the system. This was achieved by increasing or decreasing the length of the PTFE tubing used for mixing. The following lengths were tested with their corresponding residence times at $0.20 \mathrm{~mL} / \mathrm{min}: 10 \mathrm{~cm}(13.7 \mathrm{~s}), 25 \mathrm{~cm}(34.2 \mathrm{~s})$, $54 \mathrm{~cm}(73.9 \mathrm{~s}), 108 \mathrm{~cm}(147.8 \mathrm{~s}), 216 \mathrm{~cm}(295.6 \mathrm{~s})$.

Table 2. Phase separation performance for different guaiacol to anisole ratios in the organic phase using different aqueous to organic flow rate ratios.

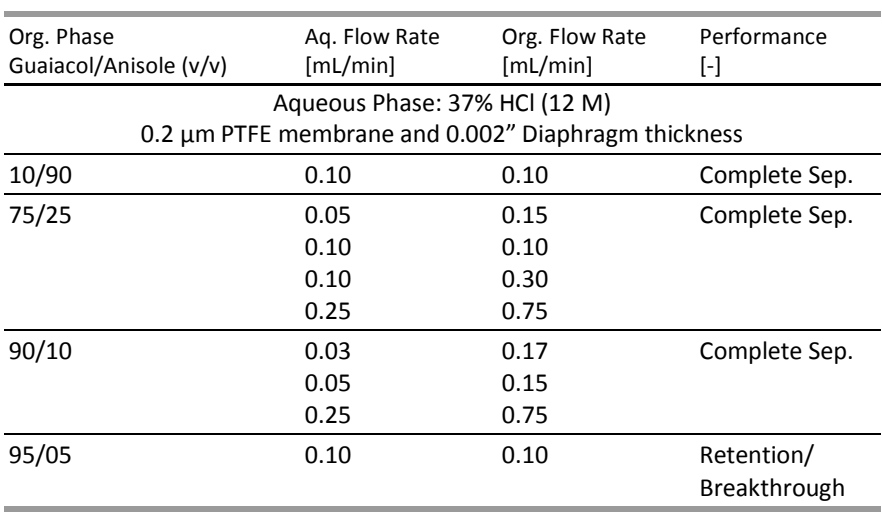

\subsection{Optimization of Continuous LLE and Phase Separation in Flow Using Non-Radioactive Metals}

Due to the harsh nature of both the aqueous and organic solvents used for this extraction, both the membrane and diaphragm had to be extremely stable. Therefore, PTFE membranes were used for all experiments described herein. Since a $0.2 \mu \mathrm{m}$ membrane and a 0.002 " diaphragm was the only combination that led to complete phase separation, it was used for all of the optimization experiments.

The composition of the organic phase needed to both selectively extract only $\mathrm{Ti}$ and have a high enough interfacial tension with the $\mathrm{HCl}$ phase that complete separation could be achieved. It was determined that extraction was directly correlated with guaiacol concentration, that is a higher guaiacol concentration led to higher extraction up to a maximum $\mathrm{Ti}$ extraction of $90 \%$ with $90 \%$ guaiacol. Guaiacol concentrations above $90 \%$ led to incomplete phase separation. A summary of the phase separation performance using various organic phase compositions is shown in Table 2.

In addition to the composition of the organic phase, the relative ratios of aqueous to organic flow rates were also varied. When comparing relative flow rate ratios of $1 / 1,1 / 3$, and $1 / 5(\mathrm{v} / \mathrm{v})$ (aq. to org.) it was determined that $1 / 1$ gave the lowest extraction. A ratio of $1 / 3$ gave a higher extraction, but $1 / 5$ did not yield a further increase in performance (see Table $\mathrm{S} 1, \mathrm{ESI}+$ ). All ratios where the aqueous flow rate was higher led to lower extraction efficiency. Therefore, a flow rate ratio of $1 / 3$ was chosen as to avoid using excess solvent. 
In order to determine the scalability and stability of the extraction, the total flow rates were scaled five-fold to a total flow rate of $1.00 \mathrm{~mL} / \mathrm{min}$, while maintaining the same flow rate ratios and residence times. The extraction performance was identical to the original scale, and the maximum extraction of $90 \%$ was still achieved at $90 \%$ guaiacol and a flow rate ratio of $1 / 3$ (Fig. 4).

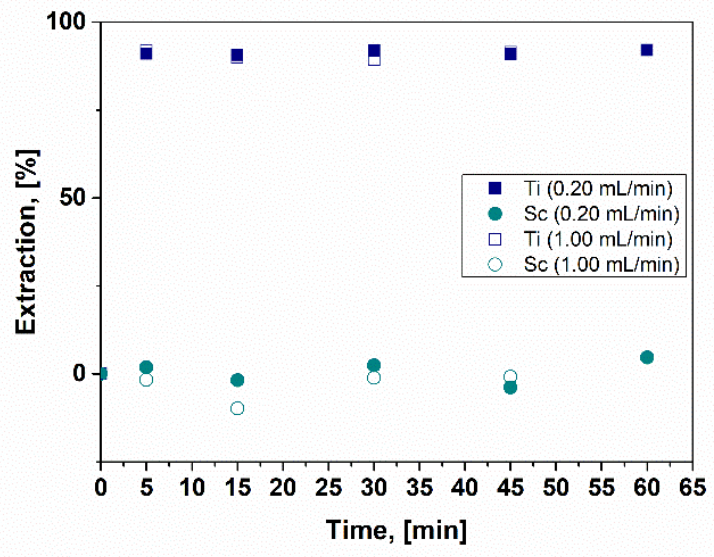

Fig. 4. Extraction performance over time for a total flow rate of $0.20 \mathrm{~mL} / \mathrm{min}$ (solid symbols) and for a five-fold scale-up at a $1.00 \mathrm{~mL} / \mathrm{min}$ (open symbols). These data show the ability for facile scale-up of the system.

The total production time is a critical parameter in this system since the radioactive $\mathrm{Ti}$ is continuously undergoing decay back to Sc $\left(t_{1 / 2}=3\right.$ hours). Therefore, the shortest residence time is desirable. Residence times of the mixing tubing were varied from $13.7 \mathrm{~s}$ up to $\sim 5 \mathrm{~min}$. The extraction efficiency was the same for all residence times. Therefore the shortest residence time was the most optimal (Fig. 5). This performance is due to the enhanced uniform mixing imparted by t-mixing, helical static mixing, and segmented flow, which allows for the equilibrium stage to be reached quickly. Overall, an organic phase consisting of $90 \%$ guaiacol $10 \%$ anisole, total flow rates of 0.20 or $1.00 \mathrm{~mL} / \mathrm{min}$, an aqueous to organic flow rate ratio of $1 / 3$, and a residence time of $13.7 \mathrm{~s}$ led to highest and most efficient extraction resulting in $90.3 \pm 1.1 \%$ extraction of Ti. No scandium extraction (whithin experimental error) was detected.

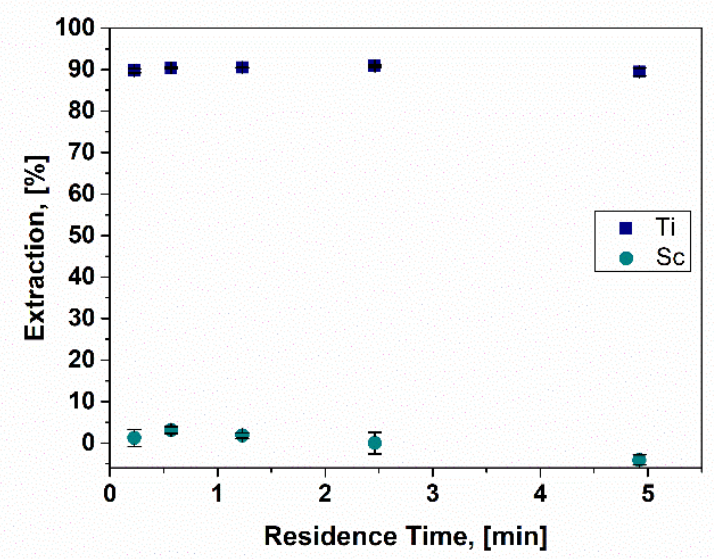

Fig. 5. Extraction performance for various different residence times (time for LLE in mixing loop from Fig. 2). The maximum $\mathrm{Ti}$ extraction (90\%) was achieved for all residence times, down to the shortest residence time of $13.7 \mathrm{~s}$.

\subsection{LLE of ${ }^{45} \mathrm{Ti}$ in flow and radiosynthesis of $\left[{ }^{45} \mathrm{Ti}\right]($ salan)Ti(dipic)}

With the extraction conditions optimized for ${ }^{\text {nat }} \mathrm{Ti}$, we turned to the radioactive isotopomer, ${ }^{45} \mathrm{Ti}$. While the concentration of Sc was comparable in both non-radioactive and radioactive cases (0.01 $\mathrm{M}$ vs. 0.03-0.13 $\mathrm{M}$ correspondingly) the concentration of the radiometal in the Sc-containing matrix solution was lower than that of its natural abundance isotopomer by 10 orders of magnitude, ranging from 1 to 10 picomoles. At these concentrations, even the trace levels of impurities or water could potentially lead to side-reaction or hydrolysis and as a consequence, change the extraction efficiencies of ${ }^{45} \mathrm{Ti}$. To our delight, the LLE of ${ }^{45} \mathrm{Ti}$ in flow using a $90 \%$ guaiacol $10 \%$ anisole mixture and a flow rate ratio of $1 / 3$ (aq. to org.), with a residence time of $13.7 \mathrm{~s}$ showed that the extraction efficiency of ${ }^{45} \mathrm{Ti}$ was consistent with that of ${ }^{\text {nat }} \mathrm{Ti}$ (84.8 $\pm 2.4 \%$ and $90.3 \pm 1.1 \%$ correspondingly), (Fig. 6). The ICPAES analysis of the aqueous phase before and after the LLE confirmed that no Sc was extracted into the organic phase.

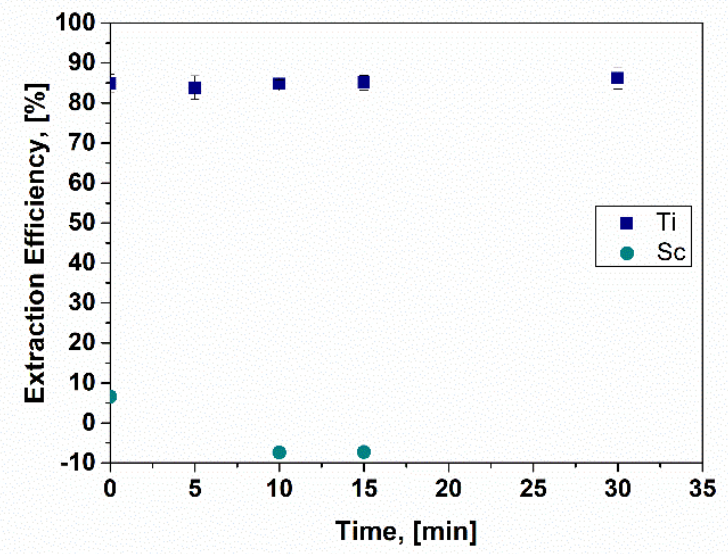

Fig. 6. Continuous LLE of ${ }^{45} \mathrm{Ti}$ at a flow rate ratio of $1 / 3$ (aq. to org.) with $90 \%$ guaiacol $10 \%$ anisole. ${ }^{45} \mathrm{Ti}$ extraction efficiency calculated from the radioactivity measurements and Sc extraction calculated from ICP-AES.

Finally, to examine if the extracted solution of ${ }^{45} \mathrm{Ti}$ can be directly used for radiolabelling, we attempted a synthesis of $\left[{ }^{45} \mathrm{Ti}\right]$ (salan)Ti(dipic) [3], a Ti-antineoplastic, previously used for 
animal ${ }^{45}$ Ti-PET and ex vivo radiotracing. ${ }^{8}$

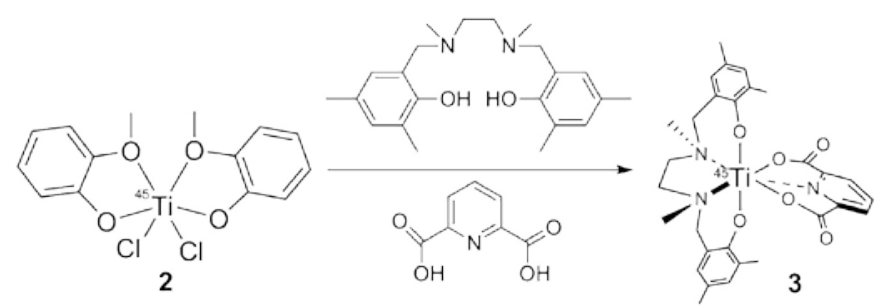

Scheme 1. Radiosynthesis of $\left[{ }^{45} \mathrm{Ti}\right]$ (salan)Ti(dipic) from ${ }^{45} \mathrm{Ti}$ extracted in the organic phase directly after LLE in flow.

To that end, the organic phase after the continuous LLE of ${ }^{45} \mathrm{Ti}$ was collected and reacted with an equimolar solution of salan and 2,6-pyridinedicarboxylic acid (dipic) in pyridine at $60^{\circ} \mathrm{C}$ (Scheme 1). An essentially complete (98.7\%) conversion to the desired product [3] was observed within $15 \mathrm{~min}$ as evidenced by radio-TLC (red peak for the product [3] and only traces of unreacted [2], green peak), proving the high quality and reactivity of extracted ${ }^{45} \mathrm{Ti}$ (Fig. 7, inset). The HPLC/radio-HPLC further confirmed the identity of the product [3] matching its retention time to that of the independently synthesized nonradioactive [ ${ }^{\text {nat }} \mathrm{Ti}$ ](salan)Ti(dipic) determined by the HPLC equipped with the UV-detector (Fig. 7).

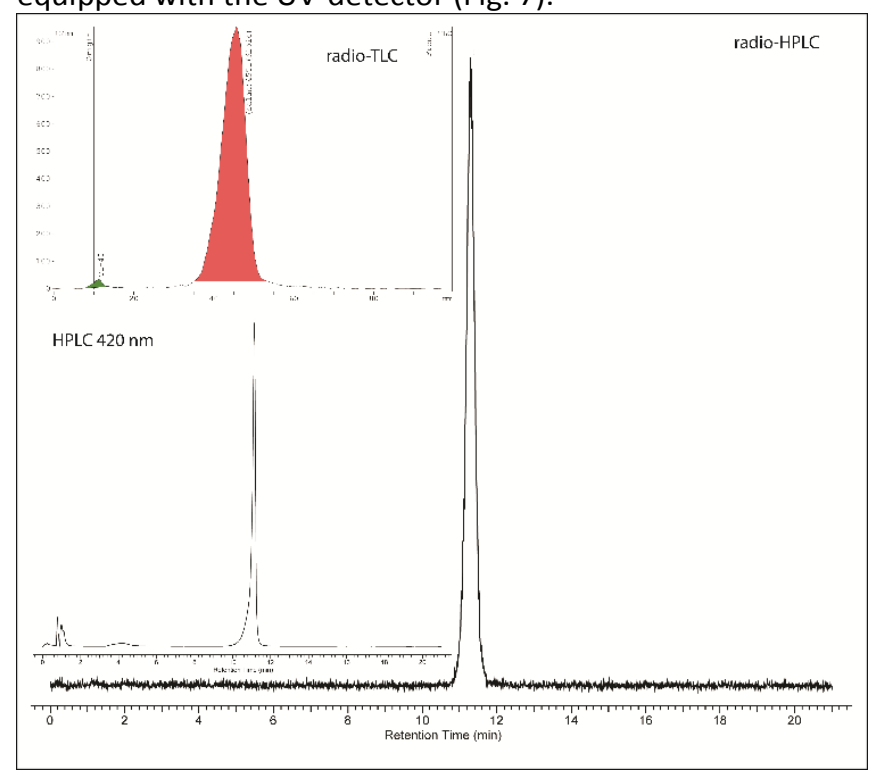

Fig. 7. Radio-HPLC of $\left[{ }^{45} \mathrm{Ti}\right]($ salan)Ti(dipic), retention time $=11.3 \mathrm{~min}$. Bottom: HPLC of (salan)Ti(dipic) at $420 \mathrm{~nm}$, retention time= $11.2 \mathrm{~min}$, insert: Radio-TLC of $\left[{ }^{45} \mathrm{Ti}\right]$ (salan)Ti(dipic) 3, $\mathrm{R}_{\mathrm{f}}=0.49$, red peak, and $\mathbf{2}$, baseline, green peak.

\section{Conclusions}

We have reported a selective liquid-liquid extraction of ${ }^{\text {nat }} \mathrm{Ti}$ and its PET radioisotope $\left({ }^{45} \mathrm{Ti}\right)$ into an organic phase from a solution containing various amount of Sc in $37 \%(12 \mathrm{M}) \mathrm{HCl}$. A membrane-based separator with integrated pressure control allowed for continuous aqueous/organic phase separation in flow. Optimization studies established a $90 \%$ guaiacol $10 \%$ anisole mixture and a flow rate ratio of $1 / 3$ (aq. to org.), with a residence time of $13.7 \mathrm{~s}$ as the optimal extraction conditions. $90.3 \% \pm 1.1$ of ${ }^{\text {nat }} \mathrm{Ti}$ were consistently extracted from a $0.01 \mathrm{M}$ solution of $\mathrm{TiCl}_{4}$ and $\mathrm{ScCl}_{3}$, while $84.8 \pm 2.4 \%$ of ${ }^{45} \mathrm{Ti}$ were extracted from 0.03-0.13 $\mathrm{M} \mathrm{ScCl}_{3}$ containing picomolar amounts of the ${ }^{45} \mathrm{Ti}$ radionuclide. As a process, the LLE in flow of ${ }^{45} \mathrm{Ti}$ was reproducible and robust. Additionally, the throughput demonstrated in this work would be capable of meeting the demand in a hospital or industrial setting. The organic phase can be directly used for ${ }^{45} \mathrm{Ti}$-radiolabelling as demonstrated by the efficient radiosynthesis of $\left[{ }^{45} \mathrm{Ti}\right]$ (salan) Ti(dipic) resulting in a $98.7 \%$ conversion.

\section{Conflicts of interest}

There are no conflicts to declare.

\section{Acknowledgements}

K.S.P. is grateful for financial support by the Danish Agency for Science, Technology and Innovation.

\section{Notes and references}

$\S$ K.S.P. and J.I. contributed equally to this work

† Electronic Supplementary Information (ESI) available:

Separator material optimization and solvent selection.

1 R. Huang, M. Wang, Y. Zhu, P. Conti and K. Chen, Curr. Top. Med. Chem., 2015, 15, 795-819.

2 D. Brasse and A. Nonat, Dalton Trans., 2015, 44, 4845-4858.

3 I. Velikyan, Molecules, 2015, 20, 12913-12943.

4 S. Kuhn, I. Spahn, B. Scholten and H. H. Coenen, Radiochim. Acta, 2015, 103, 403-409.

5 K. Ishiwata, T. Ido, M. Monma, M. Murakami, H. Fukuda, M. Kameyama, K. Yamada, S. Endo, S. Yoshioka, T. Sato and T. Matsuzawa, Int. J. Rad. Appl. Instrum. A, 1991, 42, 707-712.

6 A. L. Vāvere, R. Laforest and M. J. Welch, Nucl. Med. Biol., 2005, 32, 117-122.

7 A. L. Vāvere and M. J. Welch, J. Nucl. Med., 2005, 46, 683-690.

8 G. W. Severin, C. H. Nielsen, A. I. Jensen, J. Fonslet, A. Kjær and F. Zhuravlev, J. Med. Chem., 2015, 58, 7591-7595.

9 J. C. Merrill, R. M. Lambrecht and A. P. Wolf, Int. J. Appl. Radiat. Isot., 1978, 29, 115-116.

10 M. Sadeghi, M. Enferadi and H. Nadi, Radiochemistry, 2011, 53, 411.

11 Y. Fazaeli, M. Aboudzadeh, K. Aardaneh, T. Kakavand, F. Bayat and K. Yousefi, Nuclear Technology and Radiation Protection, 2014, 29, 28-33.

12 K. Gagnon, G. W. Severin, T. E. Barnhart, J. W. Engle, H. F. Valdovinos and R. J. Nickles, in AIP Conference Proceedings, AIP, 2012, vol. 1509, pp. 211-214.

13 K. Wang and G. Luo, Chemical Engineering Science, 2017, 169, 18-33.

14 D. M. Fries, T. Voitl and P. R. von Rohr, Chem. Eng. Technol. 2008, 31, 1182-1187.

15 K. K. R. Tetala, J. W. Swarts, B. Chen, A. E. M. Janssen and T. A. van Beek, Lab Chip, 2009, 9, 2085-2092. 
16 T. W. Phillips, J. H. Bannock and J. C. deMello, Lab Chip, 2015,

15, 2960-2967.

17 H. Breisig, M. Schmidt, H. Wolff, A. Jupke and M. Wessling, Chem. Eng. J., 2017, 307, 143-149.

18 A. Adamo, P. L. Heider, N. Weeranoppanant and K. F. Jensen, Ind. Eng. Chem. Res., 2013, 52, 10802-10808.

19 N. Weeranoppanant, A. Adamo, G. Saparbaiuly, E. Rose, C. Fleury, B. Schenkel and K. F. Jensen, Ind. Eng. Chem. Res., 2017, 56, 4095-4103.

20 A. Adamo, R. L. Beingessner, M. Behnam, J. Chen, T. F. Jamison, K. F. Jensen, J.-C. M. Monbaliu, A. S. Myerson, E. M. Revalor, D. R. Snead, T. Stelzer, N. Weeranoppanant, S. Y. Wong and P. Zhang, Science, 2016, 352, 61-67.

21 J. Imbrogno, L. Rogers, D. A. Thomas and K. F. Jensen,

ChemComm, 2018, 54, 70-73.

22 Y. Shen, N. Weeranoppanant, L. Xie, Y. Chen, M. R. Lusardi, J. Imbrogno, M. G. Bawendi and K. F. Jensen, Nanoscale, 2017, 9,

7703-7707.

23 L. Yang, N. Weeranoppanant and K. F. Jensen, Ind. Eng. Chem. Res., 2017, 56, 12184-12191.

24 E. Y. Tshuva, I. Goldberg and M. Kol, J. Am. Chem. Soc., 2000, 122, 10706-10707.

25 T. A. Immel, M. Grutzke, A.-K. Spate, U. Groth, P. Ohlschlager and T. Huhn, Chem. Commun., 2012, 48, 5790-5792.

26 V. Kislik and A. Eyal, Solvent Extr. Ion Exch., 1993, 11, 259-283.

27 J. Siikanen, J. Nucl. Med., 54, 1095.

28 R. Mondal and P. Tarafder, Microchim. Acta, 2004, 148, 327333.

29 E. de Wolf, G. van Koten and B.-J. Deelman, Chem. Soc. Rev., 1999, 28, 37-41.

30 P. Sobota, K. Przybylak, J. Utko, L. Jerzykiewicz, A. Pombeiro, M. da Silva and K. Szczegot, Chem. Eur. J., 2001, 7, 951-958.

31 M. P. Andersson, M. V. Bennetzen, A. Klamt and S. L. S. Stipp, J. Chem. Theory Comput., 2014, 10, 3401-3408. 